Historic, Archive Document

Do not assume content reflects current scientific knowledge, policies, or practices. 

431.6 Ormerod, Eleanor A.

or $5 \mathrm{~N}$

Notes on the Australian bug in South Africa. 188?. 

NO'T ES

ox

\section{THE “AUSTRALIaN BUG” (ICERYA PURCHASI)}

IN SOUTH AFRICA. 

THE AUSTRALIAN BUG IN SOUTH AFRICA. 
LONDON :

PRINTED BY WEST, NEWMAN AND CO., HATTON GARDEN, E.C. 


\title{
NO'T ES
}

ON

\section{THE AUSTRALIAN BUG}

(ICERYA PURCHASI)

IN

\section{SOUTH AFRICA.}

WITH ADDITIONAL ILLUSTRATIONS FROM S. AUSTRALIA, AND NOTES OF HISTORY AND TREATMENT FROM GOVERNMEN'T REPORTS OF THE UNITED STATES OF AMERICA.

\author{
COMPILED BY
}

ELEANOR A. ORMEROD, F. R. Met. Soc., Consulting Entomologist of the Royal Agricultural Society of England; Hom. and Corr. Mem. of the lioy. Ag. and Hort. Soc. of S. Australia; Hon. Mem. of Ent. Soc. of Ontario, and Cor\%. Mem. of Ficli Nat. Club of Ottawa, Canada; Member of Eastern Provinec Naturalists' Soc., Cape Colony.

LONDON, ENGLAND :

SIMPKIN, MARSHALL \& CO., STATIONERS' HALL COURT.

1887.

Price Threepence. 



\section{PREFACE.}

A FEW words of explanation are required as to the reasons why the compiler of this pamphlet, a resident in England, should be connected with entomological observation in Southern Africa, and the reason is this :-

Some time ago Mr. S. D. Bairstow, then President of the Eastern Province Naturalists' Society, South Africa, who had, whilst resident in England, been one of my entomological correspondents and contributors to $\mathrm{my}$ Annual Reports on Injurious Insects, wrote to me from Port Elizabeth, requesting that I would procure the identification of the species of the Australian Bug from our best European authority, and also form observations from life, and other points relatively to measures of prevention of its ravages (furnished from South Africa, or which I was begged to procure) into a plainly-worded paper which might be of popular service.

At that time, save the valuable Government Report by Prof. Trimen, little had been published on the subject in South Africa, and the researches to gain reliable information have involved correspondence with colleagues in South Africa, South Australia, North America, and elsewhere; and during the long time which has necessarily elapsed a magnificent paper, with full details both of the history of the insect itself and means of its 
prevention, has been prepared by Prof. C. V. Riley, the Entomologist of the United States of America.

The appearance of this will leave little more to be desired-probably nothing more-regarding either history or means of prevention; but when this paper was passing through the press my humbler effort was also prepared, and, as my promise had been given to publish it, I offer it accordingly. But I beg to draw the attention of the reader to this not being an exhaustive treatise; it is intended merely to embody the notes of observation in South Africa, together with some simple principles of prevention, which however can be worked out fully only by residents who know the peculiar difficulties of weather, water-supply, \&c., which have to be met.

The notes of observation are valuable in many ways, and in my own part I have endeavoured, by great care and verification, to make up for my want of local knowledge; but with regard to the full history of the pest, and how to meet its ravages, I believe the best course for all who have to deal with it is to procure and practise the excellent information and advice contained in the paper on Icerya purchasi by Prof. C. V. Riley, Entomologist of the U.S.A., published in the Report of the Commissioner of Agriculture, U.S.A., of the present year.

The authorship of the various illustrations, of the notes of original and of published observation, are acknowledged as they occur; but I desire especially to mention, with many thanks, the assistance received from the skilled authority of M. Signoret, Paris, in determining the species of $I$. purchasi, and likewise assistance from Mr. O. E. Janson, London, relatively to 
determining Rodolia iceryce as a new species. I am indebted to Mr. S. D. Bairstow for figures and a series of observations from life on Icerya purchasi or Australian Bug, and its insect destroyers in S. Africa; and to Mr. Frazer S. Crawford, Inspector under the Vine, \&c., Protection Act, and Government Lecturer on Economic Entomology, Adelaide, South Australia, for some excellent figures from life of $I$. purchasi, taken by himself at Adelaide, and information bearing on the subject. I am likewise indebted for information to the Government Report on the Australian Bug in South Africa, by Prof. Roland Trimen; and further to the kinà courtesy with which Prof. H. Comstock, of Cornell University, New York State, U.S.A., has permitted me to use his excellent figure of the pest under consideration; and besides assistance mentioned at the points where it is quoted, I must again strongly express my sense of the thoughtful and kind courtesy of Professor Riley in sending over to me in proof the forthcoming pages of his valuable paper, and other documents bearing on the subject.

ELEANOR A. ORMEROD.

Dunster Lodge, near Isleworth, England, July, $188 \%$. 



\section{THE AUSTRALIAN BUG IN SOUTH AFRICA.}
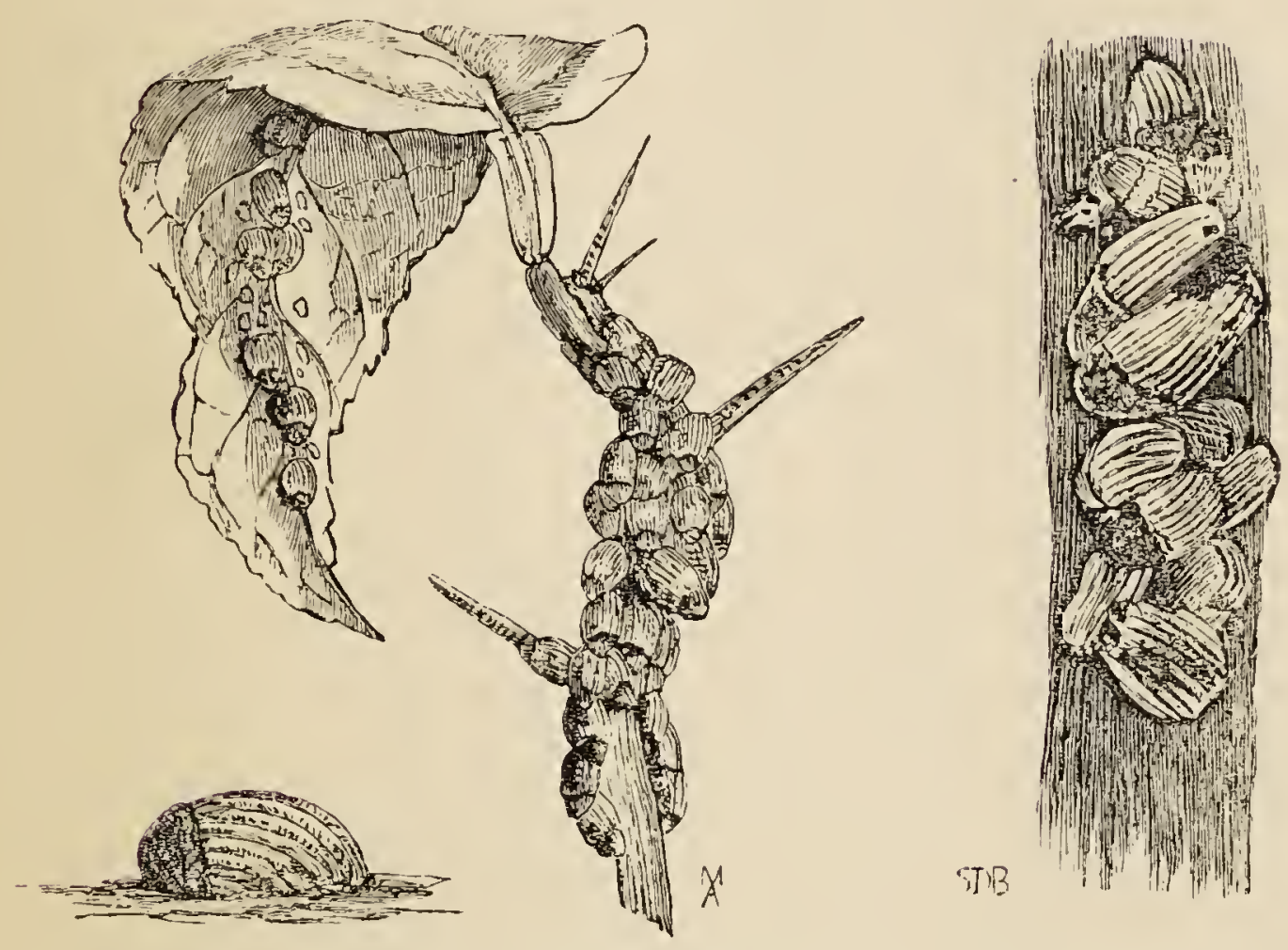

Icerya purchasi (female), much magnified; group, magnified S. African; group on twig and leaf, rather less than life-size N. American.

OF the various kinds of insect attacks which are hurtful to trees and shrubs in the South of Africa, probably those of the soft, cushiony, white, ribbed scaleinsect, commonly known as the Australian Bug (the Cottony Cushion-Scale of North America), may be considered as one of the most destructive, although this insect does not appear to be one of the native pests of the country, and little more than fourteen years have elapsed since it was first observed in the Colony. 


\section{$(2)$}

Prof. Roland Trimen, F.R.S., Curator of the South African Museum, mentions, in his Report of 1877, that he "first saw the Australian Bug in the Botanic Garden at Cape Town in the latter half of 1873, and collected the few larger ones in the small clusters observed, which did not consist of more than twenty individuals "; ; and further notes that a few days subsequently several specimens were shown to him from a garden at Claremont, with the mention that they were "entirely new" to the observer, and "appeared to be multiplying. They were found upon young black-wood trees" [Acacia sp., E. A. 0.] "obtained from the Botanic Gardens. In the course of a few months the insect increased prodigiously in number." ... "The insect gradually extended its range into all the suburbs of the town, and everywhere exhibited its unmistakable partiality for Australian plants," although at the date of writing (Feb. 5th, 1877) Prof. Trimen notes that it had "effected a lodgment on many others."

At this date it was stated, by Mr. S. D. Bairstow, of Port Elizabeth, President of the East Province Naturalists' Society (in observations sent to me by him in 1886 regarding the history and natural enemies of this pest), that the insect had spread to such an extent "in all parts of the "Eastern Province' of Cape Colony" as to give rise to an application, on the part of the resident horticulturists and agriculturists, to Prof. Trimen, Curator of the South African Museum, for information as to the nature and habits of this destructive pest, in reply to which request the Report quoted above was prepared.

The widespread ravages, and the dread of their increase, may be inferred from the mention "that municipalities drew up local laws empowering agents to enter private or public gardens and there destroy" infested trees, without regard to their value; and at the date of writing the attack had continued its onward march.

* "See Report by the Curator of the South African Museum on the insect of the family Coccide, commonly known as the Australian Bug." Government notice (Blue Book), No. 113, 1877. 


\section{$(3)$}

In a letter received by me in March, 1887, Mr. Bairstow reports, "The Australian Bug seems to be extending" operations in Bloemfontein and higher up country": this observation shows a spread over a length of country of 680 miles (if we take the town of Bloemfontein for one extremity, and Cape Town, whence it was first reported, for the other) during the fourteen year's which have passed since the first observation, thus showing an average rate of advance of little less than fifty miles a year; and a glance at a map of Southern Africa, showing the vast area of the eastern division which was infested by this pest as early as 1877 , shows its power's of naturalisation, and breadth of country occupied.

Where it came from does not appear to be proved, but the balance of opinion turns towards Australia. Prof. $H$. Comstock, the chief authority regarding this insect up to the present time, * says, in his Report, $†$ "It seems probable that it is an Australian species," and mentions that the first published notice of its appearance in the United States of America $\ddagger$ which he had been able to find was in 1877, by Dr. A. W. Saxe, of Santa Clara, who stated it as his belief that the pest was originally brought from Australia, on some plants imported by Mr. G. Gordon, of Menlo Park, in 1868, and that it spread all along the coast counties."

Prof. Comstock mentions that the specific name that has been adopted, namely, purchasi, was given this insect by Mr. Maskell, $\S$ and that "it was found on a hedge of 'kangaroo Acacia' in Auckland, New Zealand, in great numbers, but upon that single hedge alone."

In the Report of 1877 by Prof. Trimen, quoted above, he mentions that the Director of the National Museum

* When these lines were going to press I was favoured by receipt from Prof. Riley of his valuable and exhaustive paper on I. purchasi, giving full information of habits and remedies up to date, to which I refer in preface.

t Report of the Entomologist in Annual Report of the U.S. A. Department of Agriculture for 1880. Washington, 1881.

+ In the 'California Agriculturist and Artizan ' for' December, 1877.

$\S$ Trans. and Proc. New Zealand Inst., vol. xi., p. 221. 
at Melbourne identified the species as a new (viz., undescribed) Dorthesia, common in Victoria on different kinds of Acacia, and that this report of Prof. $\mathrm{M}^{\prime} \mathrm{Coy}$ confirms the conjecture that the insect would prove to be a native of Australia; and in the course of last year, on submitting specimens of this so-called Australian Bug (sent to me from Port Elizabeth, South Africa), through the hands of $\mathrm{Mr}$. O. E. Janson, London, to the eminent authority Dr. Signoret, I was favoured by him with the information that they were Icerya purchasi, Maskell, with the accompanying okservation regarding the insect, that "it is found in New Zealand and Australia."

Judging from the information brought forward up to the present time, and likewise looking at the rapid spread of the insect over a vast area, from the locality where its appearance was first recorded, it appears to be proved that it is not indigenous either in Africa or in North America, but whether it is so in Australia, and, whether it came thence direct to Cape Town or not, that the attack was set on foot by imported specimens, and has now become naturalised.

From the large numbers of females and larvæ forwarded to me by $\mathrm{Mr}$. Bairstow, I have been enabled to divide the contents of one bottle of specimens, sent over direct to me from Port Elizabeth, between Dr. Signoret, Paris; Prof. Riley, Washington; and Mr. Frazer S. Crawford, of Adelaide, South Australia, who has long bestowed much attention on this pest, besides English recipients, which may prove of service in determination of similarity of $\mathrm{S}$. African species with those of other countries.

In regard to kinds of plants attacked, the number named and their various nature points to the Australian Bug, or Icerya purchasi, Maskell, being a general pest. In Prof. Trimen's Report he mentions it being observed on oak, orange, vine, and fig, besides a large number of kinds of ornamental shrubs and garden plants, the list ranging from large trees down to strawberry plants, and 


\section{$(5)$}

the damage consequently including extensive loss of timber, ruin of valuable fruit crops, and general loss and disfigurement of ornamental shrubs, \&c.

In Mr. M. Cooke's 'Injurious Insects of California' he says*:- "This species of scale-insect I consider the most dangerous of any that infests fruit and other trees in California, as it may be said to be a general feeder : it is found on all varieties of citrus trees, deciduous fruit trees, on many varieties of ornamental trees, forest trees, and shrubs ; also on some varieties of vegetables."

Prof. H. Comstock mentions that he "found this species first during the summer of 1880, in a grove of 130 lime trees, at Santa Barbara, California. The trunks and limbs were in many cases so completely covered as to appear white, the leaves were turning yellow, and the tree was apparently dying. They had spread to surrounding orange orchards"; and in the following year "they were spreading with amazing rapidity."

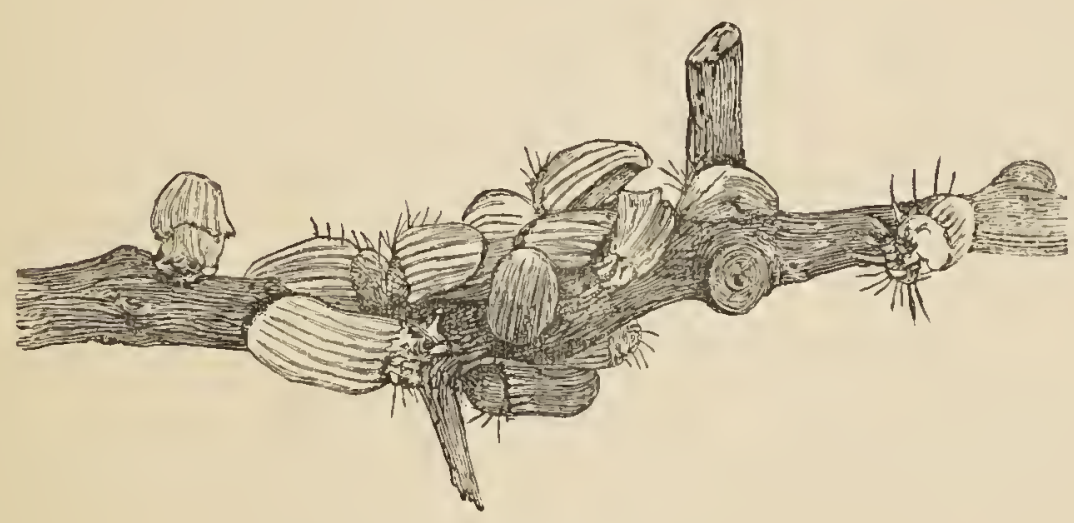

Australian Bug.

Cluster of female bugs, photographed from life at Adelaide, South Australia, by Frazer S. Crawford, Esq. $†$

The three figures of clusters of "Australian Bug,"

* "Injurious Insects of the Orchards, Vineyard," \&c. By Matthew Cooke, late Chief Executive Horticultural Officer of California. Sacramento, 1883.

t I am indebted for the above characteristic figure, as well as for those of the much magnified larva and female (pp. 15, 16) to the courtesy of Mr. Frazer Crawford, Inspector under the Vine, Fruit, and Vegetable Protection Act, and Government Lecturer on Economic Entomology in S. Australia, who has paid much attention to this pest.-E. A. O. 


\section{$(6)$}

namely, the sketch at the heading of this paper of the infested twig and leaf (taken by his kind permission from the figure in Prof. Comstock's Report on Icerya purchasi in N. America); the cluster represented on the right hand of this figure, photographed by $\mathrm{Mr}$. Bairstow in South Africa; and the cluster (see p. 5) photographed by Mr. F. Crawford in South Australia, show the very similar appearance of the females, and the similar manner in which they congregate in the three countries named.

Professor Comstock states that "The insects seem first to settle upon the leaves, preferably along the midrib, and afterwards to migrate to the twigs and branches, or even the trunk"; and Prof. Trimen similarly describes that "they attack generally the leaves, as well as the stems and branches of the plants they affect, but cluster more thickly on the latter."

The injury is caused by means of the sucker, which serves the insect as a feeding apparatus. With this it pierces into the soft tissues, and thus does harm by injuring the structure of the leaves or surface of the shoots, as well as steadily sucking away the sap of the plants.

\section{General description of the Females.}

The adult females sent from Port Elizabeth, with the white striped egg-bag attached (which to a general view looks as if it was a part of the insect), were about a quarter of an inch long, and of the shape figured on the left-hand side of fig. 1 ; that is, tortoise-shaped, or of a thick oval shape, blunt at each end, but chiefly so at the head, and arched up from each side and each end. The hinder part of the true abdomen of the "bug" is hidden by the fore part of the egg-bag, and is tilted up by the vast number of eggs which gradually accumulate beneath. The colour of the insect is of some shade of orange or salmon, for the most part covered on the upper side, and partially on the under side, by a 
whitish mealy-looking coat. When magnified this appearance is shown to be formed of little rough patches. of a white cotton-like or waxy secretion, which are largest and thickest towards the fore part of the insect, and are mixed with a sprinkling of black hairs. These hairs are set much more thickly at the edges, and form almost a fringe at the hinder part to which the white longitudinally striped egg-bag is appended.

Whether this sac is easily separable when fresh I do not know, but, after soaking some time in spirits of wine, I found it could be easily detached, and the insect attached was found to be a soft, thick, fleshy, oval mass, the place of the thorax or fore body being showed above by three slightly raised, convex, transverse ridges, each bearing a slight knob or elevation in the middle. The fore edge of the insect is thickened and slightly scalloped, and with a few ridges running from the edge to the

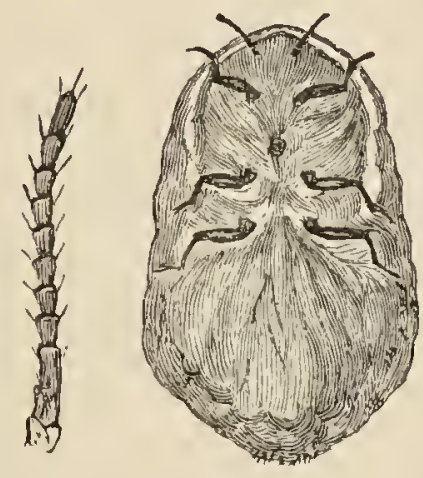

Female of Icerya purchasi; under side and antenna (much magnified).

foremost ridge. Beneath it is furnished with three pairs of legs, a pair of horns or antennæ of nine or ten joints (see fig.), and a stout sucker placed between the two foremost pairs of legs (all black or pitchy). The antennæ or horns are of nine or ten joints, of the same width throughout, excepting the lowest joint, which is somerwat wider than the others; and in the specimen examined it was not clear whether the apparently long joint immediately succeeding was of two joints or of one, slightly marked across in the centre. 


\section{$(8)$}

The figure of the antenna or horn gives a general idea of its form, but when minutely examined the terminal joint is about a quarter or fifth longer than the preceding, and it has at least four hairs, longish, but not so long as those on the club of the larval antenna, and markings are distinguishable, giving it an appearance which might be called a club, but I do not see that it is at all broader than the preceding joints.*

The egg-sac is white, formed of minute threads exuded by the insect, and is striped from the line of its attachment to the body to the hinder extremity or sides by about fifteen parallel round-topped ridges, having deep hollows between. In the case of some of the sacs which I examined the central longitudinal ridge was narrowest, even to being half the width only of the others.

The general appearance of the female is well described by the name of "Cottony Cushion-Scale" used in California, or also the name of "Ribbed Scale." Within the sac lie a multitude of oval salmon-coloured eggs, as many, it is stated, as from 200 upwards.

In Prof. Trimen's Report he states that the young hatch gradually from the eggs deposited in the cottony nidus, but appear only to leave it by degrees, till at length all have departed, and the empty skin of the dead mother alone remains behind.

Mr. Bairstow also remarked on this head:- "The bugs do not all hatch at once. I do not remark any sudden exit or uniformity and spontaneousness in clearance. ... Several days are occupied in effecting a total riddance from the oviparous mother." And he further observed of the young bugs, that " when hatched and emerging from the maternal nidus the spider-like insects are extremely active for about thirty-six hours.

* My own observations being from specimens transmitted in spirits, I cannot speak as to points of colour, amount of pubescence, flocculence, and similar points; but the structural points can be but little altered, and amongst these the difference in length of the second subcylindrical joint of the antenna of the larva from the joint immediately preceding is very noticeable (see p.10).-E. A. O. 


\section{$\left(\begin{array}{ll}9\end{array}\right)$}

Then they choose a spot for settlement, and remain stationary."

In regard to the early history of the "bug," the following notes are taken (for the most part abridged) from observations by $\mathrm{Mr}$. Bairstow, made daily, or at short intervals, from Jan. 23rd to the end of March (that is to say, during the latter part of the S. African summer, well on into its autumn); but those from Feb. 2nd to Feb. 6th are given at length in his own words, as the description of the first appearance of the white coating on the "buglets," or young larval Iceryee, and of the very peculiar, long, brittle-stalked, or fine thread-like exudation, is interesting in itself, and also as showing that this remarkable habit or condition of the larva, of which Mr. Bairstow gives his daily observations in South Africa, corresponds with what has been noticed by Prof. Comstock in his North American descriptions.

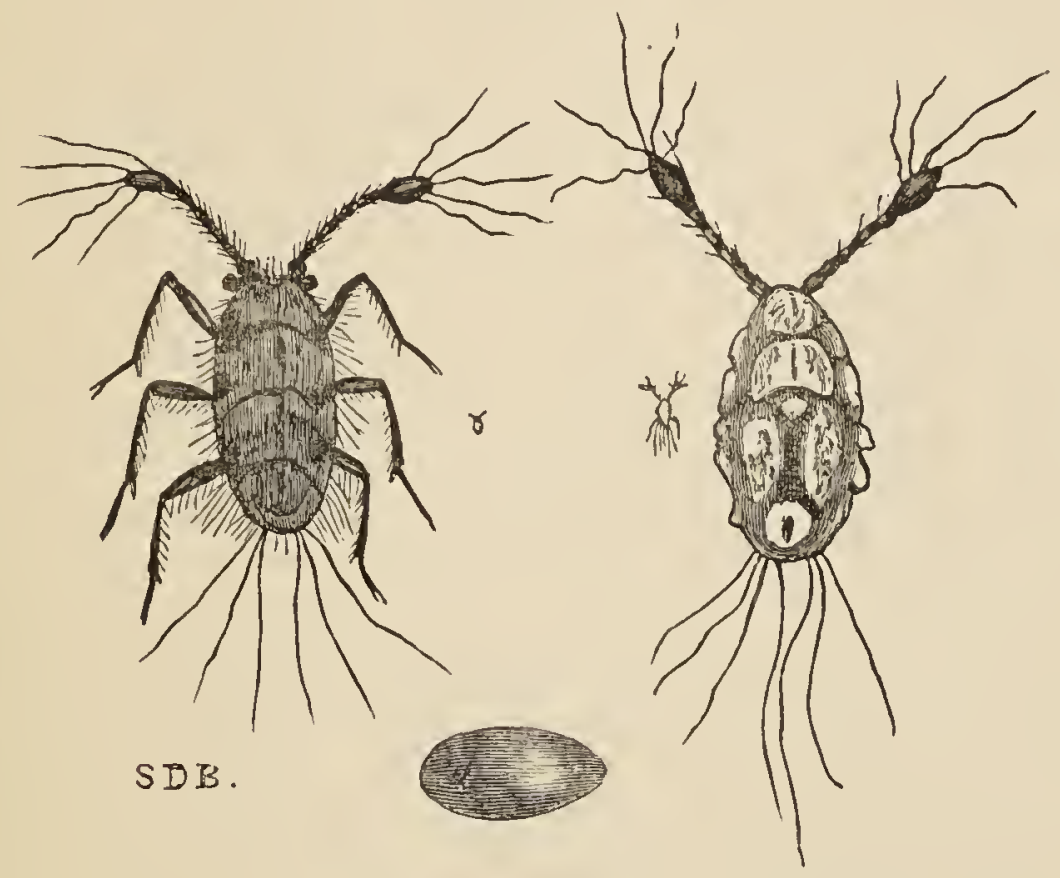

Australian Bug.

Egg and larva, much magnified; and back view of larva, much magnified, showing first growth of cottony patches.

The two figures of larvæ are taken from a series of slight pen-and-ink sketches made from life by Mr. 
Bairstow to illustrate the changes of appearance of the specimens under observation, the first showing the general appearance in an early stage of development, the second showing the patchy appearance of the fine growth of the flocculent covering.

From my own examination of the larva in the first stage (figured p. 9), as seen after being in a preservative fluid for some time, it was of a reddish tint, with black legs and antennæ and black eyes, and was furnished at the tip of the abdomen with six long fine hairs. The horns at this stage appear to me to be formed of five joints and a club. The lowest joint broad and short, about half the length and twice the width of the succeeding joint, and broadest at the farthest end from the head; the following four joints are almost cylindrical, the second of these being longer than the first and slightly contracted at the centre; a very few long scattered hairs were observable on the joints of the horns, besides those figured by Mr. Bairstow at the extremity, but I did not find the antennæ hairy throughout, as in the first fig., p. 9. For magnified figure of the larva of I. purchasi in S. Australia, photographed from life by Mr. Crawford, see p. 15.

On Jan. 23rd Mr. Bairstow placed two females on trees, and on the 31st, and up to Feb. 3rd, many young hatched. A large number of these were killed to keep the number for special observations in bounds; but on Feb. 1st, 157 newly-hatched little "bugs" were counted. Those that fell seemed unable to regain position [an important point practically-ED.]; those on the trees were excessively active, anxiously running all over the plant, as if desirous of making lodgment. Towards evening they appeared darker and somewhat glistering with rough whitish particles. On the following day (Feb. 2nd) many were dead, and the survivors mostly in parties on leaf-stems, those nearest the roots preferred.

Mr. Bairstow notes that they have "begun to assume a white appearance, which, under dissecting small power monocular microscope, consists of six clumps or clusters 
(placed as in right-hand fig., p. 9), one clump near head, followed by two clumps, and again two, and one anally. To my great astonishment there protruded from anus of each a long thread-like appendage, white and brittly, which terminated in a rotund pellucid drop of liquid This, unlike water, did not disperse on glass, but appeared to consist of a semi-solidity which could be divided as mercury with a lancet. On casting one globule against another no fusion ensued. No change in antenne.

"Feb. 3rd. Filaments produced in different insects, ranging from $\frac{1}{4}$ in. to $\frac{1}{2} \mathrm{in}$. long. Some collided together at liquid point; others crossed at irregular angles. In a few the globule was absent, but filaments seemed much more produced, reaching $\frac{3}{4}$ in. Clumps not now divided, but welded together, showing form only of prior division. Bugs assuming a white cottony appearance or glistering, as of small particles of ripe apple. Antennæ still knobbed, and all externals as before. No moult evident. Bugs stationary, almost inactive, barring slow leg movement. Many with filaments quite removed. Others mixed up indiscriminately together. Bugs about twice size, nidus included, to nalied eye as when hatched.

"Feb. 6th. First moult takes place in some. Discard white, ragged, broken cases (in metamorphosis), which are visible here and there. Present form evidently more matured, and body takes a yellowish hue, which permeates the white dorsal tufts. Filaments mostly fragmentary; antennæ still linobbed."**

* Mr. Bairstow continues, still on Feb. 6th, regarding a different form of larva noted as " condition 2" :- "Thus far first moult. Simultaneously I observe another form (whether allied or distinct remains to be proved), . . which I shall describe roughly in contrast: Not tortoise-shaped like their seniors, as suggested by Trimen, but louse-shaped; segments conspicuous whitish yellow (light lemon), legs pale, antennæ not knobbed, incilate ringed; lateral and anal hairs diminished, replaced by irregular tubular excrescences. More active, and not sticking to leaves." On the 10th these are noted as "active, and appear very white to naked eye"; and on the 16th this second condition or form is noted as "very gregarious, stationary, in clumps fixed on top of one another; no change, but growing."

On the 22nd Mr. Bairstow notes these larve distinguished as No. 2 being "as before, but parents raised on ovaries" ; on March 10th, that eggs from No. 2 had hatched, mothers shrivelled. 
On Feb. 16th the young bugs again moulted. The head portion first exposed, and in many instances the old whity abdominal skin remained a whole day attached. The colour was now salmon-red; legs and horns (which last were still knobbed, but have a more rugged appearance) black.

On Feb. 22nd Mr. Bairstow remarks of these same larvæ:-"Should imagine 'condition 1' has undergone a further moult, but invisible or overlooked, as I find fig. 8" [of illustrations sent to me, E. A. O.] "in two forms, one of which is very active, and antennæ knobless, conspicuously segmental, whilst the other is stationary, with antennæ slightly knobbed, legs inserted, only partially visible, and bases buried in a curly hairy mass.

"Feb. 27th.-All moulted to knobless antennæ.

"March 10th.-Condition 1 (fig. 8) growing rapidly. Antennæ embedded in curly nidus, and legs diminished in comparison with swollen body. Beneath many I find a young spider-like creature or bug similar to that of first emergence, but perfectly white, almost transparent." *

On March 21st another moult took place to a deeper salmon-colour than in the preceding stage, the bugs being active at first, and afterwards more stationary. Absence from home put an end to Mr. Bairstow's further observations on these specimens.

* Mr. Bairstow considers it possible that these small larvæe are from the eggs of the form he has mentioned as "condition 2," and that, if this is so, "condition 2 " produces from eggs two forms, one its own image, but very small, the other approximating in shape the young first form of cond. 1 (vide first fig., p. 9).

Not having the opportunity of personal investigation, I do not venture to offer any opinion on the above, but merely submit the notes of a practical observer; if these experiments were gone over again in the light thrown by the minute investigations reported in Prof. Riley's paper, it appears to me that we might find that some referred to the "intermediate form of female larva" recorded there as not having been previously noticed, and that prolonged observation might have shown that the small larva differing in absence of colour from the others was that of the male insect, which has not yet been described in its earliest stage. A repetition of the observation after study of the full history would be very desirable. 
Prof. Trimen notes that when the bug has reached about one-sixth of an inch in length it begins to secrete the snow-white, waxy, but cotton-like, matter, which presently forms a nest beneath the mother insect for the salmon-coloured eggs. "For some time after the white secretion" has begun to grow the Dorthesia remains tolerably active, continuing to move about, and change its feeding-ground on " the plant; but gradually, as the ova develop and the cottony secretion proportionately enlarges, its power of motion seems to decrease, and at length it remains firmly anchored to one spot by its sucker"; and as time goes on the newly-hatched young are to be found which leave the cottony nest beneath the dead mother, and, being gifted with much greater powers of locomotion at this stage than later on, seek actively for a suitable place where they may settle down to feed (see Prof. Trimen's Report).

The observations of Mr. Bairstow and Prof. Trimen, above quoted, taken together, give a large part of the life-history that is needed for practical service. We have observations of the eggs hatching in the white deposit, and the little buglets coming out and spreading actively from under the dead skin of the mother bug; also of this activity continuing more or less from about the beginning of February until at least the 21st of March; we have further the observations of the white secretion under the bug beginning when it is about the sixth of an inch long; and also we have observations of the gradually settling down into stationary condition of the female bug, as the amount of white waxy deposit increases until she becomes a mere dead husk covering the eggs and hatching young. The whole process extends over many weeks, and gives ample opportunity for immense damage to be caused by the bugs.

Whether the male of the Icerya purchasi has been observed in Africa with identification on the spot does not appear to have been reported, and therefore, as Prof. Riley has done me the favour (when these notes were going to press) to place proofs of his valuable 
paper on I. purchasi, Maskell, in my hands, I avail myself of the privilege of giving some portions of the description of the male insect, taken by him "from numerous specimens both mounted and living."

Prof. Riley states that "the adult male is a trifle over $3 \mathrm{~mm}$. in length " [that is, over the eighth of an English inch in length - E. A. O.], "and has an average wing-expanse of $7.5 \mathrm{~mm}$. The general colour is orangered." The thorax is much marked with black; some of the spiracles are black also. "The legs are also nearly black, and quite thickly furnished with short hairs. The wings are smoky black, and are covered with rounded wavy elevations, making a reticulate surface. The costa is thick and brown above the subcostal vein, which reaches costa at a trifle more than four-fifths the length of the wing. The only other vein (the median) is given off at about one-sixth of the length of the wing, and extends out into the disk a little more than one-half the wing-length. There are in addition two white lines, one extending" ... to the tip of the wing, the other curving to a point some distance below the tip. "The abdomen is slightly hairy, ... and is furnished at tip with two strong projections, each of which bears at tip four long hairs and a few shorter ones. When the insect is at rest the wings lie flat on the back." The head above is triangular, the antennæ are light brown in colour, and are composed of ten joints, of which the first is almost globular, the second somewhat longer, and the third nearly twice as long as the first, and the remaining seven joints are of about the same length as the third, "and grow successively a little more slender."

The above description is taken entirely, either abridged or in Prof. Riley's own words, from his description at pp. 480-481, in his Report as U. S. State Entomologist, published by the Commissioner of Agriculture of the United States of America, 1887. I have only availed myself of the privilege of taking such part of this description as might be available for general practical 
service from his minute and exceedingly interesting description, and I tender my grateful thanks for the

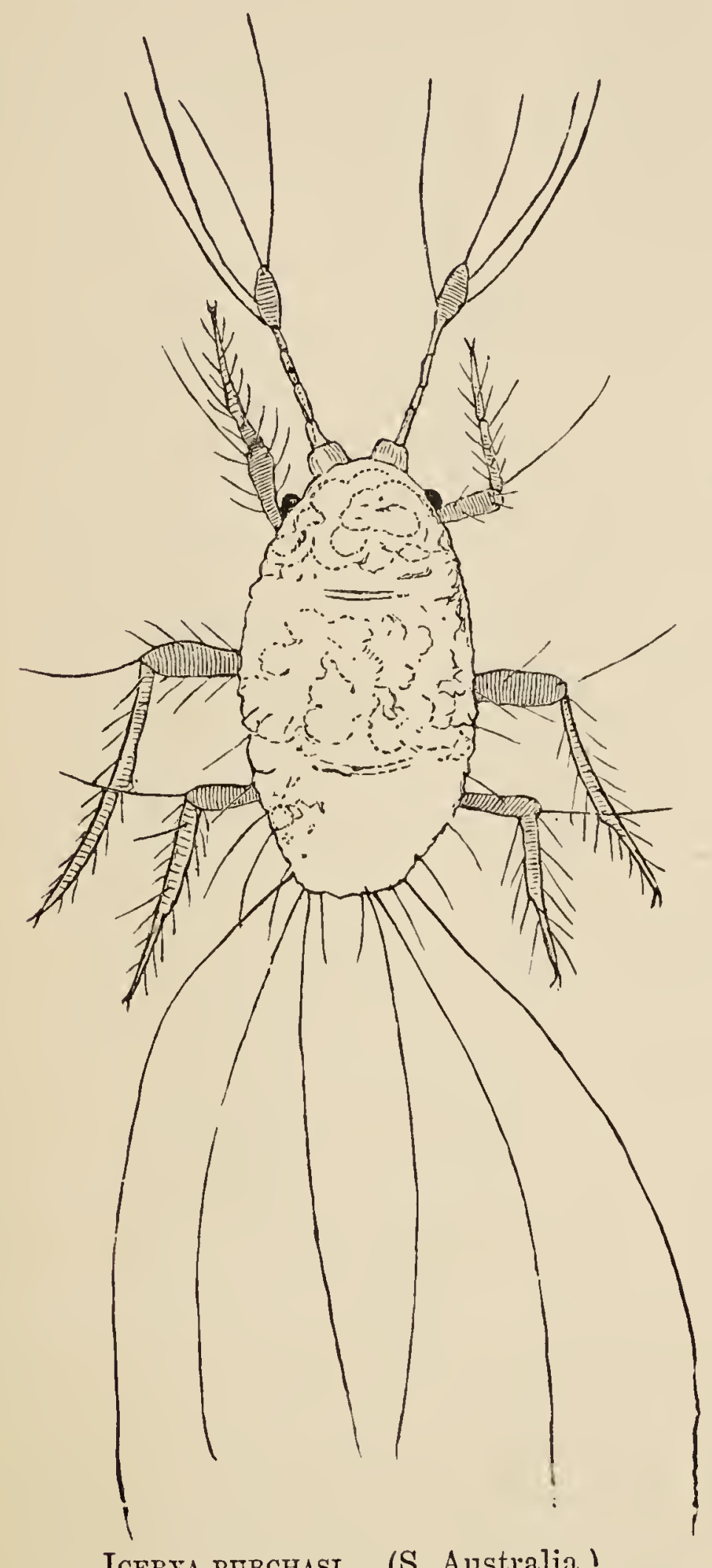

ICERYa PURChast. (S. Australia.)

Larva, enormously magnified; nat. size about 1-16th in. 


\section{$(16)$}

courteous kindness shown me by Prof. Riley in permitting me thus to benefit by his observation.

Whilst the preceding pages were passing through the press I was favoured by Mr. Frazer S. Crawford, of Adelaide, S. Australia, with the two accompanying

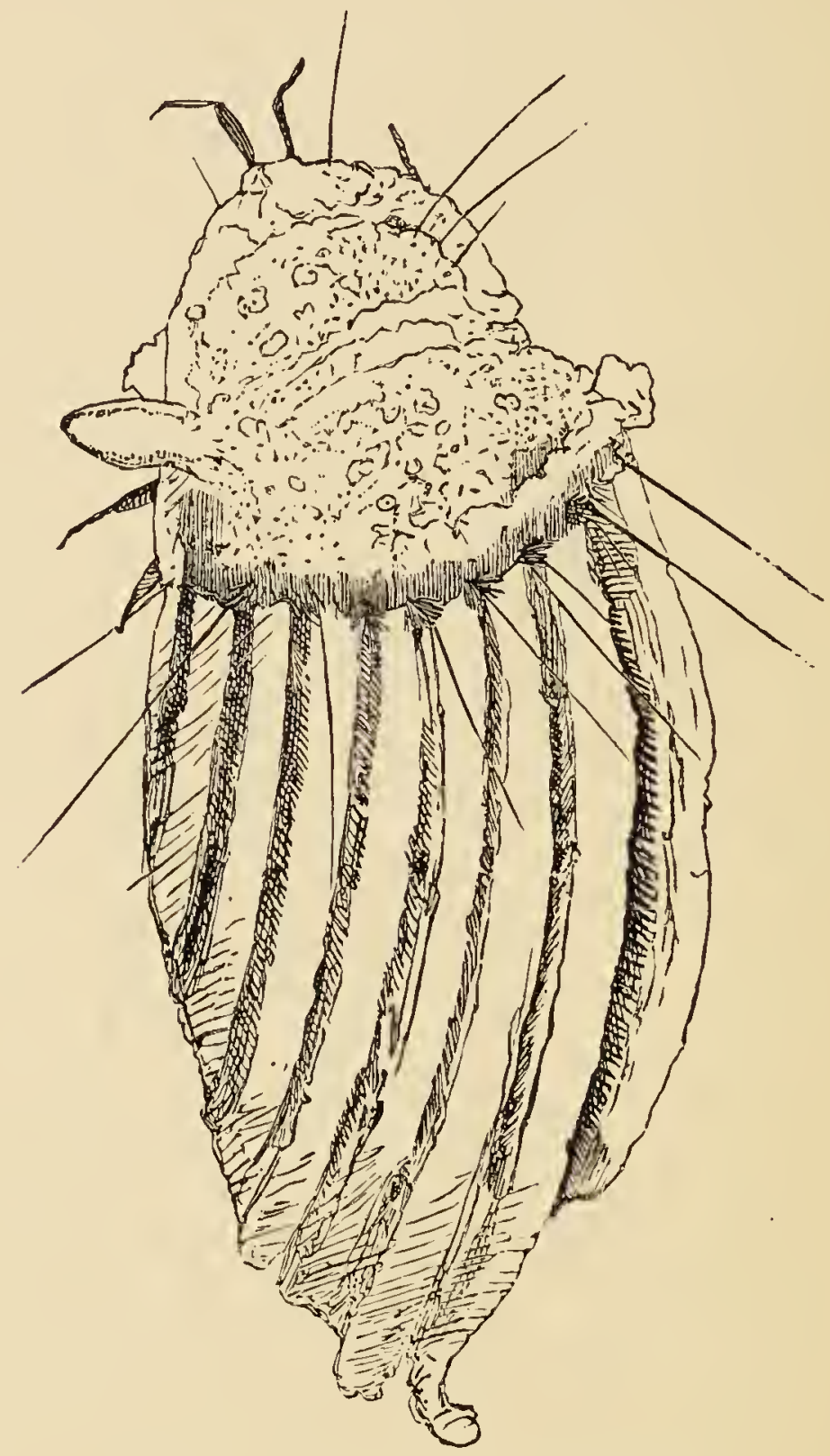

ICERYA PURChasi. (S. Australia.)

Adult female with egg-bag, greatly magnified.

drawings, giving much magnified representation of the larva and adult female of the Icerya purchasi from 
photographs taken by himself from specimens of these insects found at Adelaide. Mr. Crawford, having paid attention to these insects for some years, favoured me at the same time with some notes on habits, \&c.; but, as my object in publishing this little pamphlet was to fulfil my promise to arrange the $\mathrm{S}$. African contributions to the best of my power, and likewise since then the question of possible identity of species between what were considered formerly to be two distinct kinds under the names of $I$. purchasi and $I$. sacchari has come under consideration, I merely offer $\mathrm{Mr}$. Crawford's much magnified sketches as showing beyond doubt in the Adelaide specimen the striated nature of the egg-sac of the adult female, and also the long glassy filaments, which are characteristic distinctions of $I$. purchasi. It should be noted that, in the photo, details of structure of the legs are not given, and the fore pair, which are stretched forward, being seen edgeways, are represented narrower than if entomologically displayed.

\section{Measures of Prevention and Remedy.}

\section{Washes.}

Looking at the impossibility of clearing more than a very small proportion of the pest by hand-picking (as obviously much of it is out of reach, and likewise that most of it which may be in reach, excepting the large females, is too small to be hand-picked); also, looking at the great difficulty in the case of partially clearing trees by shaking off the pest of making sure that a quantity does not remain on the ground to creep up the trees again, it would appear that what is required is some mixture to destroy the pest on the infested tree. Something is needed-1st, which will not hurt the tree or plant; 2nd, which will hurt the "bug," or render it harmless to us whatever stage it may be in ; and $3 \mathrm{r}^{\circ}$, this mixture needs to be something that can be applied effectually with reasonable ease and at small cost. In the early days of attack soft-soap wash is alluded to as 
a thing found useful in one locality; since then its serviceableness has been brought forward elsewhere in Cape Colony, and most strongly as of use in California, and looking at the great success of soft-soap washes now used on such a large scale for destroying Aphides (no distant relations of these "bugs") in England, it appears well. worth while to give one or two of the recipes for keeping down the pest in California; and likewise some of the methods of preparing the mixtures of soft-soap and mineral oil for safe and convenient use, which have been worked out since Prof. Trimen suggested something of this nature might probably be of use.

If a minute's thought is given to the subject it will be seen that the soft- or whale-oil soap cannot fail to be beneficial by sticking on the surface of the bugs, and choking their breathing-pores, and likewise by soaking under the egg-bags of the females and destroying both the young, which are on the point of escaping, as well as those which are exposed outside. It would also be to a certain extent a preventive to the infestation being blown about the country by the wind, a matter which Mr. Bairstow especially notes as one method of spread.

One of the remedies recommended by $\mathrm{Mr}$. Matthew Cooke for destruction of this scale-insect in California* is a wash of whale-oil, or soft-soap, sulphur, and tobacco, in the proportion of one pound of the soap to a third of a pound of sulphur, the sulphur to be boiled in water for ten or fifteen minutes and the soap then added, and to each gallon of this mixture one gallon of tobacco water to be added of the strength noted below. $\dagger$ The mixture to be applied at a temperature of $130^{\circ}$ Fahr.

In the above mixture no mention is made regarding method of dissolving the sulphur, and the following recipe for a soft-soap wash with the sulphur in solution might prove serviceable:- In order to make sulphur

* See 'Injurious Insects of the Orchard,' \&c., by Matthew Cooke (late Chief Executive Horticultural Officer of California), pp. 165-167, with account of "Cottony Cushion Scale," and references to receipts for applications to destry the scale, in same work.

+ Boil 30 pounds of tobacco leaves in 30 gallons of water. 
combine with whatever liquid may be used, the sulphur should be boiled with an alkali, and the recipe has been recommended: One pound of flour of sulphur and two pounds of fresh lime boiled together in four gallons of water ; or, to save the trouble of boiling, sulphuret of lime may be purchased and used thus: of this sulphuret take four ounces, soft-soap two ounces, to each gallon of hot water; the soap and sulphuret to be well mixed before the addition of the water, which is to be gradually poured on, the mixture being stirred during the time, when a uniform fluid will be obtained without sediment, which may be used when cool enough to bear the hand, and has been found to destroy insect pests effectually and quickly. This may be used as a syringing, or a dip for infested shoots, or well rubbed with a brush into infested bark. The mixture, like other soft-soap washes, may be thrown when requisite to a height of several yards by large garden-engines, such as are used in Hop-fields in England. If it is needed higher, and water and apparatus are attainable, trees of even considerable height may be "washed" by the help of a fire-engine. I have had this done in England under special circumstances with great success.

The following note by Mr. W. G. Klee, State Inspector of Fruit Pests in California, regards application of various forms of soft-soap wash for the extermination of the Australian Bug, or "Cottony Cushion Scale," as it is well named in California, on small evergreen trees, or on deciduous trees when out of leaf or lopped back to the main trunk or branches. [It will be observed that the ingredients of the wash that are given in full detail are especially directed to be boiled. Probably much danger and damage would be spared if attention was always directed to the point that soft-soap washes should be raised to boiling-point in the process of mixing. —ED.] Mr. Klee states:- " "For all deciduous trees ... we recommend one-fourth of a pound of concentrated lye, one-fourth of a pound of whale-oil soap, to one gallon of water. Before treating the tree cut off the tops down to the main branches and burn them. 
"For evergreens the summer wash recommended last summer is useful, and will not hurt healthy foliage: dissolve 30 pounds whale-oil soap ( 80 per cent. soap at the most costing 5 cents per pound) in 60 gallons of water by heating the whole thoroughly. Boil 3 pounds of lye (American concentrated lye is what we have used) with 6 pounds of sulphur and a couple of gallons of water. When thoroughly dissolved it is a dark brown liquid (chemically sulphide of soda). Mix the two, the soap and the sulphide of soda, well, and allow them to boil for about half an hour, then add about 90 gallons of water to the mixture, and it is ready for use.

"Apply it warm, at about $130^{\circ}$ Fahr., by means of a spray-pump. Used warm its effect is better, and less material is required than when cold. It must, however, be remembered that the minute scales are especially numerous on the under side of leaves. This fact makes the extermination on a large tree in full foliage almost impossible. Only small trees may be successfully treated in this way. Large trees must be either deprived of their foliage or cut down to a few limbs.

"Neither of these methods can be safely applied on tender trees during a season when sharp frost may be looked for. A spraying should, however, be done, as it will check their spread most effectually.

"Too great pains cannot be taken in removing infected limbs, as the insect spreads often in this way. A canvas should be spread under the trees so that none of the insects can escape. When the tree has been treated spread hot ashes around its base, and apply tight-fitting bands smeared with a greasy substance around the trunk to prevent any insects reascending." -W. G. KLEE, Inspector of Fruit Trees.t

* The point of spread of the pest being likely to be encouraged, rather than checked, by infested boughs being removed without due care as to what becomes of the dislodged and shaken-off insects, is so important that $I$ have given it in italics.-ED.

+ Bulletin No. 4 of State Board of Horticulture of California. Winter washes recommended by the State Inspector of Fruit Pests. Sacramento, State Office, 1887. 


\section{$(21)$}

\section{Washes of Soft-soap in combination with Petro- leum, Paraffin, or other Mineral Oils.}

In the Report on Australian Bug, prepared by Prof. R. Trimen, he mentions that "it might be worth while to try one of the antidotes used against the Phylloxera in France, viz., petroleum and water," \&,c.; and since the date of the Report the serviceableness of mineral oils as insecticides, when so combined with soft-soap and water that they may be diluted further as may be needed for use without risk of the oil and water separating again, has been strongly brought forward under the direction of the Department of Agriculture of the United States, and reported on at length by Prof. Riley.

The U.S.A. plan is to add one gallon of water, in which a quarter of a pound of soft-soap (or any other coarse soap preferred) has been well dissolved, boiling or hot, to two gallons of petroleum or other mineral oil. The mixture is then churned, as it were, together by means of a spray-nozzled syringe, or double-action pump, for ten minutes, by means of which the oil, soap, and water are so thoroughly combined that the mixture settles down into a cream-like consistency, and does not, if the operation has been properly performed, separate again. This is used diluted with some three or four times its bulk of water for a watering; if required for a wash, at least nine times its bulk is needed,- that is, three gallons of "Emulsion," as it is termed, make thirty gallons of wash. Warning is given that care must be taken with each new crop to ascertain the strength that can be borne by the leafage; this of course varies with the age of the leaves, as well as the nature of the crop.

In my own experiments with this mixture $I$ increased the quantity of soft-soap, and for Hop-plants I should consider it would be desirable to double the proportion of soft-soap and lessen that of the paraffin to at least a sixth.

An addition of some amount of paraffin to soft-soap wash has been shown to be serviceable by the experiments of Mr. Ward at Stoke Edith in 1883, and in the last 
season. The proportions used by him for large quantities are 12 pounds of soft-soap and half a gallon of paraffin to 100 gallons of hot water, the mixture stirred well together and used when cool; the nearer boiling that the water is used the better the paraffin mixes. This wash is found to be very effective in killing the Aphides without injuring the plant or the burr.

For low shrubs or plants to which application could be made by means of a watering-can, the mixture of which the details of preparation and convenient method of storing are given as follows, would probably be found serviceable :-

"To eight parts of soft water add one part of black (soft) soap, and boil briskly for a few minutes until the soap is thoroughly dissolved. While boiling add paraffin, or any similar mineral oil, and boil for a minute or two longer, when the whole will be thoroughly amalgamated, ${ }^{*}$ and, if bottled and securely corked while warm, it will remain so, and be fit for use at any time when required. The strength of the solution of course depends on the amount of mineral oil in it, and it can be easily reduced to the proper power by mixing it with soft water as it is wanted for use."

Mr. Malcolm Dumn gives me the following notes as to the method he finds most convenient for mixing the application :- "In practice I boil the proper proportions of soap and water together, and when ready I fill this into ordinary wine-bottles, which have been placed in boiling water. The bottles are about half-filled with the lye, and then the paraffin is poured into them, two gills being put into each bottle. The bottles are then filled up with the boiling lye, corked at once, and stored away for use.

"When required for use a bottle of the mixture is poured into a four-gallon watering-pot, which is filled up with soft water, and is ready for use, at a strength of one wine-glass of paraffin (half a gill) to one gallon of water."

* For field use the immediate application would save all need of storing. For garden use the arrangement of bottling saves much risk from careless workers, as the exact amount to be used can be given out. 
Mr. Dunn further notes that the important point is the proportion of the soap and water:- "Eight parts water and one part soft-soap thoroughly amalgamated form the lye which takes mineral oil, and thoroughly amalgamates with whatever proportion of this may be added,- - that is to say, the paraffin may be put into the boiling soap and water in any quantity, and the whole will mix together of an equal strength throughout. Heat helps much in quickly producing thorough amalgamation of all the ingredients, and hence I have stated that they should be mixed in a boiling state.

"Few plants in a green state will stand a strength of four wine-glasses (two gills) to the gallon, but at the same time it is not necessary to use it so strong for even Scaleinsects, the most difficult to kill of all ordinary plantpests.

"One wine-glass full of paraffin to a gallon of water is strong enough to kill Aphides, and such soft insects; two wine-glasses for Thrips, and three wine-glasses for Scale is our 'regulation' strength. The tender young fronds of ferns and the young green grouths of most plants will not be safe if over one wine-glass to the gallon is used."*

The following note regarding spread of Australian Bug during the year 1886, and means considered to be useful in checking its increase, was forwarded me by favour of Mr. F. von Schade, of Wynberg :- " The Australian Bug (Dorthesia) has made its appearance in the village of Oudtshoorn, and we advise the property-holders to exert much vigilance in exterminating it at once. Putrid blood has proved a good exterminator of the bug. 'The stems and branches of trees must be painted with the blood, the smell of which attracts numerous insects which devour the bug. Ostrich droppings boiled in water and the solution syringed on the higher branches of trees has also been found very effective. Then there is the solution made of tobacco and whale-soap for washing and syringing."- - Wynberg Times,' July 31st, 1886.

* 'Eighth Report of Observations of Injurious Insects,' 1884, published 1885. By E. A. Ormerod. Simpkin, Mar'shall \& Co., London, England. 


\section{$(24)$}

[If the blood could be applied to the stems and branches of the trees as a painting, there would not be difficulty in applying a good painting or scrubbing with a thick soft-soap solution, which would probably have an excellent effect.-ED.]

In regard to methods of application one great difficulty is how to throw the fluids high enough to reach the upper boughs and foliage of moderate-sized trees. Of this Prof. Comstock says that the difficulty is best met by using some kind of force-pump, by which mixtures can be sprayed on the infested plants. The pump he recommends is formed of two brass tubes, one working telescopically within the other; a hose is fastened to one end, and a rose can be attached to the other; an arrangement of valves allows water to pass into the pump through the hose, but will not allow it to return. Thus, when the smaller tube is pulled out the pump is filled to its greatest capacity; by pushing this tube back the water can be ejected with considerable force through the rose in a fine spray. By using a nozzle with a single opening a stream can be thrown to a greater distance. In this way the topmost leaves of any orchard tree can be reached. In applying liquids on a large scale, as upon extensive orchards, the work can be done rapidly by placing the mixture in a barrel upon a waggon, and pumping directly from this barrel. It is noted that from the great difficulty of wetting every part of the tree by a single application, that probably several will be necessary.*

\section{Destruction by Hand-picising and shaking dorwn the Bug Fron Infested trees.}

Prof. Trimen states that he regards it as of "the first importance to destroy all the larger specimens, for from these legions of young are perpetually proceeding, and

* 'Report of the Entomologist of the United States Department of Agriculture for the year 1880.' By H. Comstock IVashington, 1881. 
the effectual destruction of a single gravid female means that of at least 150 or 200 young ones." He mentions. that he has found "that the larger specimens may often be detached by shaking a plant, or, in the case of trees, striking the branches smartly with a stick. When this is done a cloth, or sheets of paper should be spread under the shaken or beaten branches to catch the insects. as they drop, otherwise some of them will break on striking the ground and the eggs or young escape." $\mathrm{He}$ further advises in the same Report, "that all the insects. collected together should be burnt forthwith, as they resist immersion in water for a long time, and the eggs. or minute young in the mass of white secretion are unaffected by it. Crushing the old ones is also only partly effectual, many of the enclosed young escaping the pressure unhurt."**

Mr. S. D. Bairstow also draws attention to the benefit of destroying the female, and the ease with which the young may be shaken from the trees.

As these young bugs are so active and fall off so readily it would appear very desirable, where boughs have been lopped or infested trees felled, that these boughs or trees should be burnt (or charred on the surface) at once, and on the spot, or else, as is pointed out in the Report of the Inspector of Fruit Trees in California, published in the present year (1887), the removal of the boughs may in itself be a means of spreading the pest.

Tarred bands, or bands of any sticky composition smeared round the lower part of the stems of fruit or timber trees, would effectually stop traffic of the "bug" up the trunks so long as the bands remained moist and sticky; but, if the thing be possible, some more secure method of gathering the fallen, active, young bugs, or. preventing their ranging off to some of the low-growing plants near, than what has been named seems needed.

In U.S.A. practice the plan of beating injurious. insects down on to cloths treated with some fluid or

* 'Report on Australian Bug,' by Prof. R. Trimen, previously quoted. 
mixture which will temporarily paralyse the grubs or insects as they fall on to it, or possibly kill them outright, has been recommended, and in the present case it appears quite admissible that the cloths recommended to be placed under the trees to be beaten should be so prepared beforehand. There are many mixtures of petroleum or other mineral oils which would probably answer the purposes. The fact of the oil soon separating from water would not matter in this case, and the cloths might be dipped in a mere mixture of the petroleum and water and used wet, or they might be drenched over (when laid down) with soft-soap and petroleum wash, which would presumably prevent any of these little creatures straying away; or a good swilling on to the ground of soft-soap wash would be a great preventive of wandering.

In England, for prevention of wandering from a given point, it is sometimes found useful to circumscribe a small area with a line of wet tar, and where there were only the droppings from a few trees or the infestation in a limited spot to be temporarily dealt with, it might save all trouble to run a little furrow (just to save waste in application), and to pour some tar along it, renewing it for a day or two if necessary; but in whatever way it is managed, it is obvious, from the remark of the Inspector of Fruit Pests of California, quoted at p. 20, that the point of the spread of the attack from the pest being dispersed in removing the infected trees requires much consideration.

On Aug. 21st, 1886, Mr. Bairstow wrote:-“I notice that the large female attacks the black-wood roots most fiercely in the winter time. Just now" [winter in Cape Colony-ED.] "in St. George's Park the ground in some parts is simply alive-snowy-with them." At this period a little care and attention must prove amazingly beneficial.

How far mechanical measures can be brought to bear on such a state of things as that above described can only be certainly known by trial, but it occurs whether 
something might not be done towards gathering a large amount of the pests off the grass by running a machine over it, made on the principle of a lawn-mowing machine, with brushes instead of cutters. It would on the face of the thing appear likely that, by a little arrangement to allow of the brushes just catching on the edge of the box so as to free themselves of the bugs sticking on to them, much might be cleared from the ground and swept up into the box and destroyed. If all other measures failed, good hearty sweeping of the grass with brooms or brushes frequently dipped in soft-soap solution would clear an appreciable amount, and would at least be better than leaving the creatures to be dispersed as chance might cause.

When the trees, or groves of trees, are infested, it is manifest that it is only by the most wholesale or broad scale measures that anything can be done to check attack, but (looking at the great variety of plants mentioned as liable to be infested by this pest from the quantities creeping in the grass upwards) it is very plain that there is no hope of stopping the spread of the pest by the destruction of only a portion of its haunts, such as fruit or timber trees, and that general measures are greatly needed, and a careful watch to prevent attack getting hold.

Amongst these the danger of transmission should in every way be guarded against; the processes of removal of parts of trees which have been felled to get rid of the bug cannot be too often pointed out, as being exceedingly likely to cause carriage also of the pest, and likewise all plants received from doubtful localities should be carefully investigated; and no one with any thought for the welfare of his neighbours should allow the smallest plant with the "bug" on it to be carried from his grounds.

But with regard to applications that may be serviceable for use against the Australian Bug (the Cottony CushionScale of North America), it would be equally presumptuous and unnecessary at this date to offer any special suggestions on this subject, as in the Report of 
the Commissioner of Agriculture of the United States, before mentioned, it will be found in the observations tendered by Prof. Riley, from Mr. D. W. Coquillett, and likewise from Mr. Albert Koebele, of Alameda, California, that these points are minutely dealt with.

In these observations are given as to effects, good or bad, of caustic potash and caustic soda, hard soap, softsoap, kerosene emulsions, tobacco, tobacco-soap, sheepdip, vinegar and Paris-green, bisulphide of carbon, resinsoap, whale-oil, \&c.; and, besides methods of and appliances for throwing the washes, and methods of mixing or preparing the same, notes are given of little less than 153 experiments tried by Mr. Albert Koebele, with mention of material used, proportion of water added, and the results of the application.

Before offering some remarks on two of the African parasites of this insect, I close this attempt to offer some observations on the Icerya purchasi, its habits and treatment in South Africa, with the strong recommendation to all concerned to endeavour as soon as possible to gain possession of the paper, which I have already alluded to, by Prof. Riley, and there study the history, the nature, and the means of prevention of the pest in the trustworthy, masterly, and exhaustive reports with which he benefits all who suffer from the scourge. I desire also to add one little word on my own account, - that it was before we knew the subject was to be taken up by such a master-hand that I was applied to from Port Elizabeth to gain for them from our greatest European authority the scientific name of the so-called Australian Bug found there, and to form for them a simple paper which such as had both little time and care to read scientific treatises might learn something from. To do this to the best of my power has involved correspondence with the most distant parts of the world, and long delays, as I desired to make up for my own inability to study the subject in its adopted land by the most careful personal verification, study of such specimens as were sent to me, and comparison of documents. Now that my little 
attempt is ready the far superior work supersedes the necessity for it; but, having prepared it, I give it as it stands without alteration, save that, availing myself of Prof. Riley's courtesy, I have given a short account from his observations which he has placed in my hands of the male insect; and I feel in recommending all readers to procure and study Prof. Riley's paper, that at least one powerful "method of prevention" is placed before them, which, if duly used, will bring about a most beneficial lessening in amount of this hurtful pest, well known as "The Scourge of South Africa."

\section{Means of Prevention of Increase.}

\section{Inseact Enemies.}

The carnivorous larva or maggot of a species of Chrysopa or Lace-winged Fly, or "Golden Eye," and also the grubs of a Coccinellid or Ladybird, have been observed by Mr. Bairstow to do much good by destroying the young Australian Bugs, just at hatching time, within the sac of the female.

Of these Mr. Bairstow says:-_"The Coccinella is by far our best friend. It is proving a perfect god-send in destroying the perfected young in nidus of the female 'bug.' The larva buries itself in the gravid female and completely destroys her progeny, the dead carcase falling to the ground; and it eats the 'bug' not only when it is young, but when it (the Coccinella) has developed to beetle condition. I have taken as many as five or six young bugs out of the inside of one of these Coccinella or Ladybird Beetles. The changes from grub to beetle are rapidly passed through, as with other Coccinellide."

Its efficacy cannot be over-estimated, and an importation of the Coccinella to infested regions would be certain to be of service.-S. D. B.

This species of South African Coccinellid is of the size and sliape figured, and may be generally described as black, with a blood-red spot in the centre at the base of the wing-cases; and clothed with thick short down above; the under side and legs reddish, and also downy. 
As this "Ladybird" does not appear to have been previously described, I placed it in the hands of $\mathrm{Mr}_{\mathrm{r}}$. Oliver E. Janson, of London, England, who was good enough to examine it for me; and on it proving to be a species as yet undescribed of the genus Rodolia icerya, n.sp. Rodolia, it has appeared desirable to mark it by a specific name pointing to its serviceable habits of destruction of the Icerya-as the Rodolia icerya, Janson, n. sp. I append Mr. Janson's technical description,* and also give the following more general note of appearance with which he faroured me:-

"I think if you mention in your description its very convex form, its shape a little longer than broad, with the thorax narrower than the elytra, and rounded at the side, and the very peculiar short flattened legs, with the tibiæ angulated and grooved for the reception of the tarsi, together with the colour (black, with a blood-red spot in the centre at the base of the elytra; under side and legs red-brown), and the peculiar dusty or powdered appearance of the upper side produced by the dense short pubescence with which it is clothed, it would be easily distinguished from any other of the Coccinellidre."-O.E.J.

The slight sketch of the maggot sent by Mr. Bairstow shows it to have the somewhat elongate form common to larvæ of this family, three pairs of claw-legs and jaws

* Rodolia icerya, n.sp. - Almost hemispherical, a little longer than broad, and slightly narrowed behind; above very finely and closely punctured, and rather densely clothed with fine grey pubescence; shining black, with a large semicircular blood-red spot at the base of the elytra, enclosing the scutellum. Head flattened; inner margin of the eyes straight; antennæ, palpi, and labrum, red. Thorax produced and rounded posteriorly, truncate in front of the scutellum, strongly produced and rounded at the sides, the lateral margin slightly reflexed, anterior margin narrowly testaceous. Scutellum elongate-triangular, the apex acute. Elytra impressed on each side of the scutellum, the humeral callus very prominent, humeral angles somewhat produced anteriorly, rounded, and slightly elevated. Under side and legs pale red, strongly punctured, and with fine grey pubescence; epipleuræ strongly concave, black; tibire strongly emarginate for the reception of the tarsi, the outer edge strongly but obtusely angulated and fringed with long grey hairs. Length $4-5$ millim. 


\section{$(31)$}

(which it uses to good purposes), and that the sides of the segments were furnished with pencils of hairs.
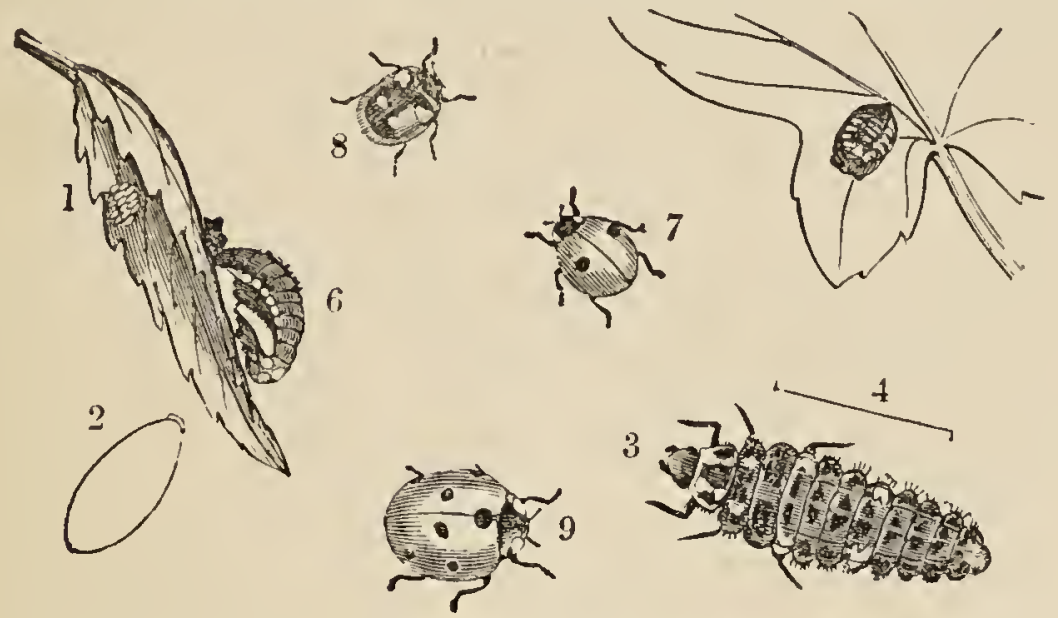

English Ladybirds, with egg and larva magnified ; chrysalis nat. size.*

The figure of the pupa- or chrysalis-case represents this stage as passed in the typical manner of this family, namely, that after the larva has become full-grown it fastens itself by the end of its tail to a leaf or some other point of attachment, and then rolls off its maggot-skin up to the end of the body, and waits thus affixed till the pupal changes have been completed, and the Ladybird emerges from the pupa or chrysalis.

The great benefit received from various kinds of Coccinellide in this special matter of destroying Scale-insects has been strongly drawn attention to by Prof. W. Saunders in his excellent work on 'Insects Injurious to Fruits' in America. He notices that the predaceous insects which feed indiscriminately on Scale-insects, and "Mealy Bug" (that is, do not limit their attacks to only one kind of Coccus), consist mainly of various species of Ladybirds. Some of these American kinds, he mentions, are found from the Atlantic to the Pacific; other's "are restricted

* As Mr. Bairstow's pen-and-ink sketch of the larva and chrysalis was not sufficiently detailed for engraving, I give (by permission of Messris. Blackie, of Glasgow) a figure showing various kinds of Ladybird Beetles (or Coccinellida); also a larva or grub, and a chrysalis natural size and much magnified, which give a general idea of the appearance in these two stages; and, in the case of the chrysalis, of the manner in which the creature is fastened to the supporting leaf or twig by the tip of the tail. -E. A. O. 
to the Pacific coast, or are more abundant there. Ladybirds both in their larval and in their perfect state devour Scale-insects, Mealy Bugs, and Aphides."*

Whether the Rodolia icerya could be moved from its own country has yet to be seen, but in its native land its spread by transmission to infested districts is mentioned by Mr. Bairstow as being very satisfactorily carried out. On Aug. 21st, 1886, he noted that he had forwarded "scores of detachments of this Ladybird to different people," and the iniormation he was receiving from many quarters of the effect of this predaceous insect in thinningoff the numbers of the bug was most satisfactory. On Sept. 25th requests had become exceedingly numerous for transmission of live specimens of the Ladybird and another Bug-destroying insect, to be presently alluded to; and Mr. Bairstow remarked that he found the Rodolia the best of all remedies, and on Oct. 30th he reported that the "Australian Bug is quite cleared out of my garden by Rodolia."

Another of the enemies of the Australian Bug by which the increase of this pest in S. Africa is materially checked is a species of Chrysopa or "Golden Eye," one of the Hemerobiidce or "Lace-wings," a family of which the grubs or larvæ are sometimes known, from one large item of their food, as Aphis Lions. Of these grubs Mr. Bairstow says :- "I do not wish it to be understood that this singular larva preys solely upon Dorthesia" (Australian Bug.-E. A. O.). "...... But that the larva decidedly prefers Dorthesia, if it can be obtained, I rest assured, both from out-of-door observations and practical experiments. As the insect appears to be as yet undescribed, I have suggested that the specific name of icerye should be bestowed on it (provisionally at least) as well as on the Rodolia, with reference to the special article of its food. In common with other species of the Hemerobiide or Lace-wings the perfect insect flies in the day time, but is not readily disturbed when at rest. It is short-lived."

* 'Insects Injurious to Fruit,' by Prof. W. Saunders, F.R.S.C., Philadelphia, U.S.A., 1883. 
"The imago is of the size and shape figured, with four iridescent azure and pink tinted transparent wings, brownish green body, and yellow head and thorax. Eyes

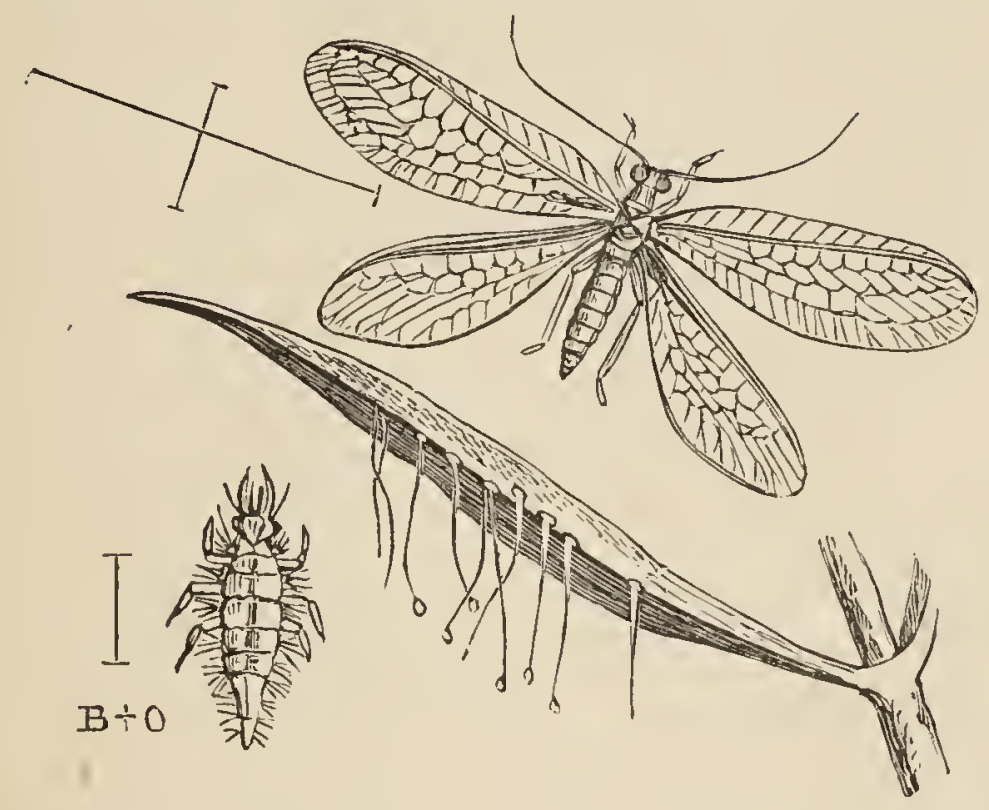

Chrysopa (? iceryce, n. sp.). - Insect and larva, magnified, with lines showing nat. size. (Sketch showing appearance of stalked eggs of Hemerobiide).

deep purple, with a rusty tinge, and encircled with red. Antennæ long and slender. Wing-expanse about seveneighths of an inch. Length of body about a quarter of an inch."

The larva or grub is of the shape copied from $\mathrm{Mr}$. Bairstow's sketch (see figure, with the natural size accompanying), and of a dirty brown colour above, and whitish below (for full description see note); and has the remarkable habit, in common with others of its kind, of piling a covering of scraps on its own back.*

* Description of Larva of Chrysopa (? icerya, n. sp.)-Length $\frac{1}{4}$ inch. Dirty brown on back, darkest where the woolly deposit is situated. Beneath: semitransparent dirty grey, with deep brown divisional and segmental markings. A longitudinal centre band forming grey irregularly shaped squares of varied dimensions centred on each, with dark brown semitransparent spot and lateral marks of grey. Under prothorax and thorax external organs are set off with a pale salmon-pink colour, very variable in different specimens. Tarsal tips and anus black. The lateral tubercles on each segment are setiferous and very conspicuous, 1 st, 2 nd, and 3rd being most prominent. First, dirty white, edged with black, and setæ corresponding; other's dull white at base, and paler setæ. Ocelli 


\section{$(34)$}

Mr. Bairstow thus notes the method of operation of the grub:-Travelling up and down a branch, he at last approached a good fat specimen of Dorthesia, and began dragging with his mandibles pieces of the woolly nidus, which he carefully arranged, and throwing his head backward steadily deposited the fragments on his body until it was quite covered. This I found was afterwards utilised in metamorphosis for a domicile to protect it in chrysalis state, and being coated inside with some gummy secretion, made a hard exterior and capital fortress; but in wrenching away the white nest from the female bug, he was demolishing the only protection for the eggs and young buglets sheltered within. Having at last pulled away enough to expose the residents, he seized on them one by one, and, after sucking all vitality out, flung away the empty skin.

For further observation ten or twelve of these "Aphis Lions" were placed with six gravid female "bugs," one of which was opened by a cut across the white waxy eggnest, thus exposing the eggs and young within, which were reckoned by Mr. Bairstow as amounting to as many as five hundred, if all hatched. At the end of the first day the whole collection in the opened female had been destroyed by the voracious little Aphis Lions; they then attacked the other female bugs, and at the end of five day's scarcely a bugling survived.

"The observer further remarks that he has noticed "scores of times" that well-developed females which he saw on a branch on one afternoon would next morning show only as broken egg-bags, empty and torn to shreds, and as they could not have all hatched and got away, it appeared plain there was something at work "struggling to assist in keeping a proper balance, and this, after search, was found in the shape of a Hemerobius grub, a small larva with big jaws, demolishing Dorthesia in scores."

Mr. Bairstow remarks that the voracious larva is much

black, also longitudinal markings or laminæ reaching from near base of mandibles to second pair of tubercles, black and conspicuous. Jaws about one-sixth length of body; palpi and antennæ prominent.-S.D.B. 
assisted in catching its prey by the structure which enables it to use its long jaws in various directions, and thus grasp the eggs as well as capture the young bugs; also that it is readily detected in its native haunts either as a grub or pupa by the powdery mass of covering which it assumes, and which when pilfered from the bug gives it a completely snowflake appearance; or when at rest it might be passed over as a small mass of spider's web.

The precise description of the egg has not been given, but it is the nature of the Hemerobiida, to which family this Golden Eye belongs, for the female to discharge a small quantity of sticky matter in the process of laying each egg. This draws out in the operation into a long fine thread, at the free extremity of which the egg is borne very much like the head of a pin on its stem. The sketch of eggs added to those of the larva and perfect insect of this Goiden Eye merely conveys an idea of the general method of egg-deposit of this family.**

Insect-enemies of I. purchasi at Adelaide, S. Australia.

In the course of correspondence with Mr. Frazer S. Crawford, of Adelaide, S. Australia, t on Icerya purchasi, he favoured me with the following communication:-

"For the last three years I have had a colony of $I$. purchasi in a lemon tree in my garden; the other day, being desirous of obtaining some living specimens, I found that every one had been destroyed, nor a single young one could I find after a prolonged search. This has been the result of two parasites. First, the larva of one of our native Coccinellide; but the principal exterminator has been a dipterous insect in the shape of a minute metallic greenish black fly.......

"Now the parasite has so completely exterminated the host" that Mr. Crawford considers it likely to destroy it

* An excellent account of the general life-history of the Hemerobiidce will be found in Prof. Westwood's 'Introd. to Classification of Insects,' vol. ii., p. 47.

t Government Inspector under the Vine, Fruit, and Vegetables Protection Act, and Lecturer on Economic Entomology, \&c. 


\section{$(36)$}

in the case under his notice, and suggested measures of transmittal to S. Africa of this serviceable destroyer.

A few specimens of the twa-winged fly were sent over to me, but unfortunately, either in transmittal or in process of unpacking, they were so much injured that, after submission to various of our best authorities, it has been found totally impossible to identify them with certainty; but some slight amount of information may be conveyed by the following rough and general description of the best specimen, in its dried condition :-

Length about one-sixteenth of an inch; colour dark; abdomen green and hairy (hairs apparently on the edges of the segments). Thorax cylindrical; head not quite as wide as the thorax, nearly straight behind, convex before, with large compound eyes of a reddish colour, each occupying about one-third of the width of the head as seen from above. The abdomen appeared somewhat narrowed to the extremity and bent under the insect, but it was impossible to say whether this was the natural position and form.

The only perfect leg remaining had the tibia (or shank) widened, and the tarsus (or foot) exceedingly fine and slender. The neuration of the wing is conveyed in the figure given of the portion secured.

The above description is useless for scientific purposes, from the antennæ and other points needed for identification being absent, but may help in conveying some general idea of the appearance of the fly.

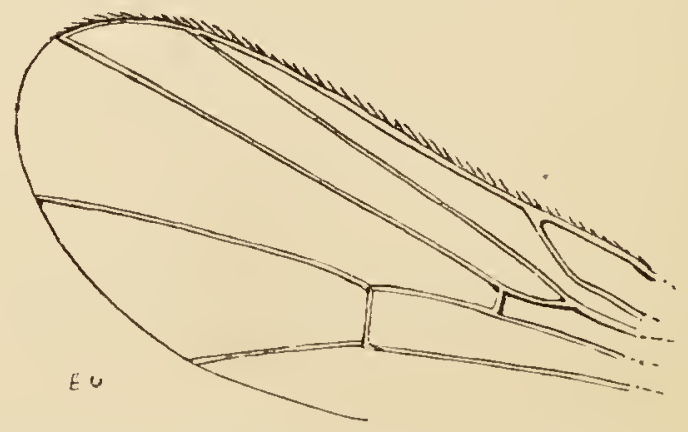

Portion of wing of Dipterous fly (much magnified), of which the larva are predaceous on Icerya purchasi at Adelaide, S. Australia.

PRINTED BY WEST, NEWMAN AND CO., HATTON GARDEN, LONDON, E.C. 


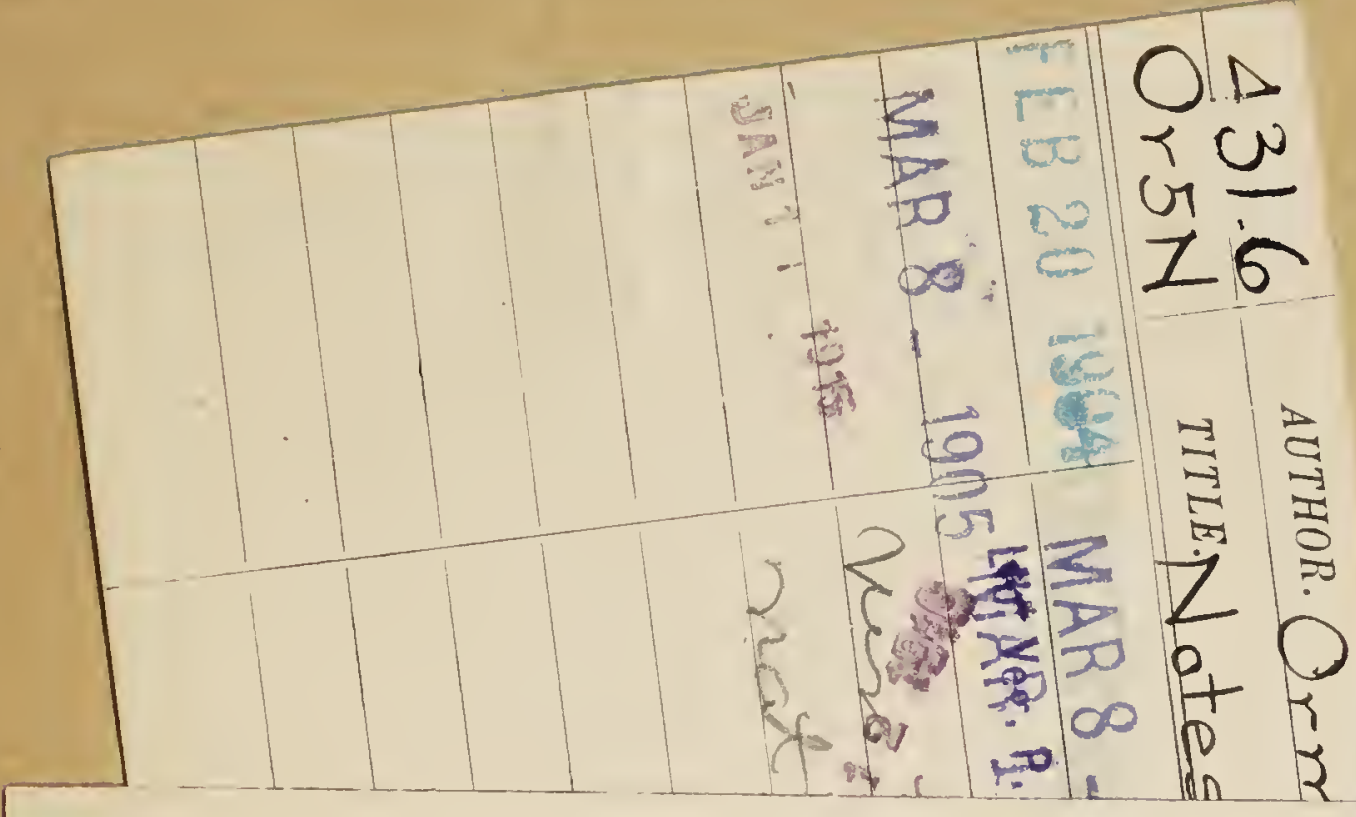




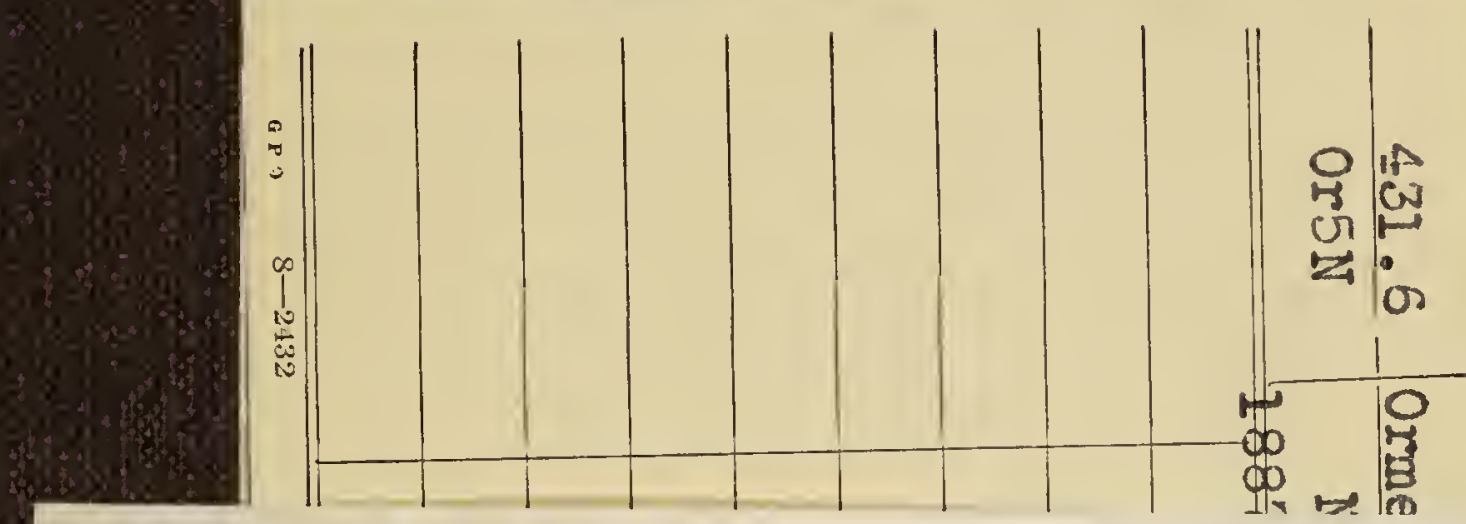
